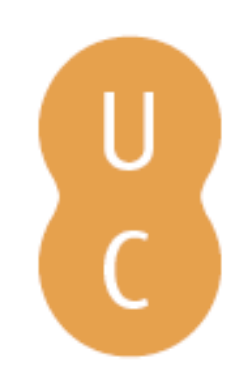

pnmbalina

\title{
História e Sociologia da profissão docente: estudos em circulação no Brasil e em Portugal (1990-2010)
}

\author{
Autor(es): $\quad$ Xavier, Libania \\ Publicado por: Imprensa da Universidade de Coimbra \\ URL \\ persistente: URI:http://hdl.handle.net/10316.2/38581 \\ DOI: $\quad$ DOI:http://dx.doi.org/10.14195/978-989-26-0646-0_10 \\ Accessed : $\quad$ 26-Apr-2023 13:32:44
}

A navegação consulta e descarregamento dos títulos inseridos nas Bibliotecas Digitais UC Digitalis, UC Pombalina e UC Impactum, pressupõem a aceitação plena e sem reservas dos Termos e Condições de Uso destas Bibliotecas Digitais, disponíveis em https://digitalis.uc.pt/pt-pt/termos.

Conforme exposto nos referidos Termos e Condições de Uso, o descarregamento de títulos de acesso restrito requer uma licença válida de autorização devendo o utilizador aceder ao(s) documento(s) a partir de um endereço de IP da instituição detentora da supramencionada licença.

Ao utilizador é apenas permitido o descarregamento para uso pessoal, pelo que o emprego do(s) título(s) descarregado(s) para outro fim, designadamente comercial, carece de autorização do respetivo autor ou editor da obra.

Na medida em que todas as obras da UC Digitalis se encontram protegidas pelo Código do Direito de Autor e Direitos Conexos e demais legislação aplicável, toda a cópia, parcial ou total, deste documento, nos casos em que é legalmente admitida, deverá conter ou fazer-se acompanhar por este aviso.

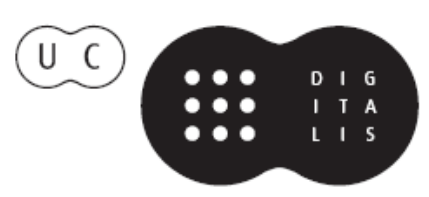




\section{História e Sociologia da Profissão Docente: estudos em Circulação no Brasil e em Portugal (1990-2010)}

LIBANIA XAVIER

ANA WALESKA MENDONÇA

Visando contribuir para o debate sobre a historiografia portuguesa e brasileira no século xx e xxI, o presente capítulo destaca as contribuições de estudos de caráter sócio-histórico, em circulação no Brasil e em Portugal que, nos últimos trinta anos, têm exercido influência na definição de questões, temas e referências teóricas na produção acadêmica sobre a história da profissão docente. O texto se encontra estruturado em cinco tópicos. O primeiro versa sobre a produção sociológica de língua francesa que vem sendo apropriada pelos pesquisadores de ambos os países, com destaque para as contribuições de François Dubet e Claude Dubar. O segundo tópico aborda duas pesquisas de língua inglesa que contemplam a temática do ponto de vista dos modos de produção das identidades docentes. O terceiro tópico contempla pesquisas que abordam as condições de desenvolvimento do trabalho docente, centrando o foco sobre as ambiguidades que permeiam a questão da autonomia profissional e os processos que confluem para o mal estar profissional e a proletarização. O quarto tópico destaca a contribuição do pesquisador português Antonio Nóvoa sobre a profissionalização docente, numa abordagem geral sobre a construção social e histórica da profissão na Europa Ocidental. O quinto e último tópico aborda a produção historiográfica recente, resultante do intercâmbio entre pesquisadores portugueses e brasileiros. 
Nas considerações finais são avaliadas as potencialidades teóricas e práticas do conjunto de estudos selecionados.

\section{A sociologia francesa aplicada ao estudo da profissão docente}

A referência à abordagem sociológica francesa sobre socialização e identidade profissional tem orientado boa parte dos estudos sobre profissão docente, no Brasil e em Portugal. Nesses estudos, prevalece a preocupação por explicar a ideia recorrente de crise das instituições escolares e compreender suas repercussões sobre o trabalho docente. Tais questões acabam por incentivar o estudo das negociações identitárias, chamando atenção para os processos de construção - individual e coletiva - das identidades docentes. Os pesquisadores estão buscando perceber em que medida a observação das negociações em torno da construção de identidades profissionais por parte dos docentes podem revelar aspectos ainda pouco explorados a respeito dos constrangimentos políticos, das interações sociais e das dimensões simbólicas que permeiam as dinâmicas identitárias desse grupo profissional. Nessa linha, destaca-se a publicação de François Dubet, publicado na França em 2002, ainda sem tradução para o português, mas circulando em língua espanhola em reedição de 2006. Outra contribuição destacada provém do livro intitulado A socialização: construção das identidades sociais e profissionais, de Claude Dubar, publicado em 1997 em Portugal pela Porto Editora e, no Brasil, pela Martins Fontes em reimpressão de 2005.

A abordagem de Dubet (2002) sobre as profissões vinculadas à educação, à saúde e ao serviço social o leva a caracterizar a profissão docente, assim como a dos profissionais da saúde e da assistência social, como profissões que se remetem ao trabalbo sobre o outro, ou seja, atividades assalariadas, profissionais e reconhecidas que visam explicitamente a transformar o outro, ou, conjunto das atividades profissionais que participam da socialização dos indivíduos (opus cit, p. 9). A categoria proposta pelo autor de trabalbo sobre o outro não só nos parece explicativa de certas especificidades da profissão docente, como é sugestiva a diferenciação que este autor estabelece entre os professores primários (instituteurs) e os professores secundários 
(professeurs), remetendo-se, particularmente, à situação francesa. Partindo do pressuposto de que o trabalho sobre o outro, nas suas origens, foi concebido como parte importante de um programa institucional, que designa particularmente um modo de socialização e um tipo de relação com o outro.

Nesse apecto, Dubet estabelece distinções entre a forma como se configurou o trabalho do professor primário e o do professor secundário. Conforme assinalou o autor, após a fase inicial de constituição da escola primária na França, em finais do século XIx, início do século $\mathrm{xx}$, em que o professor primário se configurou como o instituidor da República (daí a sua própria denominação), esta escola sofreu uma mudança significativa no seu programa institucional, passando os professores desse segmento a se constituir em especialistas da infância, da psicologia e da didática (idem, p. 94). Para o sociólogo, o que identifica, nos dias atuais, o professor primário é o cuidado com a criança.

Na sua perspectiva, a situação é bem diferente no caso da escola secundária, percebida nas suas origens (e não só) como escola da grande cultura e da elite. A esse respeito, Dubet faz uma afirmativa desafiadora, quando assume que no ensino secundário, todos os atores, ou quase todos sentem a nostalgia de um liceu tradicional, aquele que eles conheceram ou aquele com que eles sonharam (ibidem, p. 131). Para o autor, neste programa institucional, a vocação dos professores se definiu menos pelo ofício (métier) e pela pedagogia, do que pela disciplina ensinada (ibidem, p. 132). Embora avalie que essa imagem encontra-se, hoje, entre a crise e a mutação, sob o choque da massificação do ensino, esta ainda estaria impactando a prática desses professores divididos entre o seu estatuto (lugar que lhe é atribuído no sistema) e o seu ofício (= métier - a maneira como ele realiza seu trabalho). Esta distinção é particularmente importante, porque aponta para a necessidade de se levar em conta as diferenças internas desse grupo profissional, quando se consideram os diversos segmentos do ensino.

No referido livro, Dubet assinala que, há quase meio século, a escola se viu submetida a duas críticas, ambas radicais. A primeira reduz a instituição e o trabalho escolar a uma vontade de poder e de dominação. Mais liberal e mais política, a segunda crítica opõe a índole fechada das instituições à diversidade e ao fluxo constante das demandas sociais, de informações e de políticas 
públicas. Frente a esses fluxos, as instituições se mostram como burocracias rígidas, testemunhos de um passado dominado pelo Estado centralizador. Como observou o autor, a consciência de viver em um mundo aberto, pluralista e desagregado também provém de que a maior parte das instituições escolares perdeu o seu monopólio sobre a difusão de conhecimentos socialmente relevantes. Isto porque, na atualidade, as crianças encontram acesso a muitos outros meios que lhes abrem distintos universos culturais e a cultura escolar se torna uma cultura entre outras, mais exigente e oficial, mas não é mais a única. Ele explica que essa perda do monopólio cria um sentimento de diminuição da legitimidade e da influência da escola e dos professores, quando, jamais, os aparatos escolares tiveram tanto poder e tanta influência sobre o destino de cada um.

Para este autor, a sociologia crítica também afetou as instituições escolares, na medida em que os profissionais adquiriram uma dificuldade a mais para lidar com a indisciplina. Esta se transformou num problema, porque aqueles responsáveis por impor a disciplina, os professores, devem, também, percebê-las como manifestações justas. Assim, ao mesmo tempo em que sofreram uma perda de legitimidade de sua autoridade, os professores se viram obrigados a lidar com o aumento das resistências dos usuários dessas instituições em submeter-se às normas da disciplina escolar, muito frequentemente distantes das referências culturais de seu meio de origem. O controle da disciplina tem requerido dos professores um trabalho de justificação permanente, para o que eles necessitam mobilizar constantemente os seus atrativos pessoais. Tal situação já seria suficiente para se falar, não apenas na crise de identidade perante demandas variadas e não raro divergentes a que estão sujeitos os professores na sociedade contemporânea, como também indica a emergência de aspectos típicos do que se convencionou chamar de mal estar profissional. Voltaremos a este assunto no tópico 4.

A outra referência a que aludimos anteriormente é a do sociólogo francês Claude Dubar (1997; 2005). No livro A Socialização, o autor analisa os mecanismos de construção das identidades profissionais que se desenvolvem ao longo toda a trajetória profissional dos indivíduos e se articulam ao próprio processo de socialização. O tema é abordado a partir de dois eixos fundamentais, a saber: 1) um eixo sincrônico, ligado a um contexto de ação e a uma 
definição de situação, em um espaço culturalmente marcado, e 2) um eixo diacrônico ligado a uma trajetória subjetiva e a uma interpretação da história pessoal, socialmente construída. Como demonstra o autor, é na articulação desses dois eixos que cada um se define simultaneamente, como ator de um sistema determinado e produto de uma trajetória específica.

A elucidação das formas de identificação socialmente pertinentes em uma dada esfera de atuações - objetivas, subjetivas e reconhecidas socialmente, as quais o autor denomina formas identitárias - articula dois sentidos dos termos socialização e identidade: a socialização relacional dos atores em interação em um contexto de ação (as identidades para o outro) e a socialização biográfica dos atores engajados em uma trajetória social (as identidades para si). Resultam, por fim, em uma concepção de ator que se define a um só tempo pela estrutura de sua ação e pela história de sua formação. Desse modo, a teoria sociológica apresentada por Dubar tem como ponto central a articulação entre dois processos identitários heterogêneos. O primeiro, que diz respeito à atribuição de identidade pelas instituições e pelos agentes diretamente em interação com o indivíduo, deve ser analisado dentro dos sistemas de ação no qual o indivíduo está inserido e resulta de relações de força entre os atores envolvidos e da legitimidade das categorias utilizadas, que são impostas coletivamente e que levam a formas variáveis de etiquetagem. O outro processo refere-se à incorporação da identidade pelos próprios indivíduos, e só pode ser analisado considerando-se as trajetórias sociais por meio das quais os indivíduos constroem identidades para si. Nesse caso, a legitimidade irá depender daquilo que tem subjetivamente importância para o indivíduo.

Nessa linha, a construção das identidades se faz, portanto, na articulação entre os sistemas de ação que propõem identidades virtuais e as trajetórias vividas pelos sujeitos, por meio e no seio das quais se formam as identidades reais, em um processo constante de negociação, que se realiza dentro de um determinado campo de possibilidades. Para esse autor, tanto as esferas do trabalho e do emprego, quanto a da formação constituem domínios pertinentes das identificações sociais dos indivíduos, sempre pensadas como configurações relativamente estáveis, mas igualmente evolutivas. Essa análise nos parece particularmente sugestiva numa dupla direção: a relação entre biografia e identidade profissional e, igualmente, a relação inter-geracional. 
Dubar considera que todas as identidades são construções históricas - sociais e de linguagem - e, como tal, são acompanhadas por racionalizações e reinterpretações que às vezes se fazem passar por essências intemporais. Mesmo considerando que a formação da identidade constitui essencialmente um problema de geração, ele alerta que cada geração a constrói com base nas categorias e nas posições herdadas da geração precedente, mas também através das estratégias identitárias desenvolvidas nas instituições pelas quais os indivíduos passam e que eles contribuem para transformar. Esta construção identitária adquire uma importância particular nos campos do trabalho, do emprego e da formação, nos quais os indivíduos buscam conquistar o reconhecimento de sua competência profissional, ao mesmo tempo em que participam na atribuição dos status sociais a indivíduos e grupos.

Em que pese o caráter sociológico de seus estudos, tanto Dubet quanto Dubar atribuem forte ênfase à abordagem histórica dos processos de construção social das profissões. Nessa perspectiva, enquanto o primeiro enquadra a consolidação e a crise das instituições escolares e da valorização social do professor nos limites do projeto de constituição da modernidade ocidental, o segundo chama a atenção para a cadeia geracional que constrói e remodela, incessantemente, as identidades profissionais, os desenhos institucionais e as dinâmicas sociais que se definem e reconfiguram os modos de atuação pessoal e profissional. Nesse aspecto, tanto o pesquisador britânico Martin Lawn, quanto a norte-americana Mary Dalton desenvolvem uma abordagem que se apoia na análise dos mecanismos de gestão ou, de modo mais enfático nos modos de fabricação das identidades docentes. De modo inverso, Ivor Goodson chama atenção para a importância do foco sobre os indivíduos e suas subjetividades, apoiado no estudo das histórias de vida de professores.

\section{Abordagens em língua inglesa sobre as identidades docentes}

Uma abordagem que incide sobre a questão da produção e gestão da identidade docente provém dos estudos de Martin Lawn (2000), para quem o Estado promove a produção de identidades dos docentes através de suas Leis e Regulamentos, de seus discursos e intervenções na mídia, dos programas 
de formação, certificação e qualificação de professores, das políticas de publicação dirigidas aos professores, entre outras formas de intervenção. Lawn destaca, ainda, que a produção de uma dada identidade é móvel e flexível o suficiente para se adaptar aos projetos políticos em curso, de modo a recompor o controle do Estado sobre a ação e o trabalho docente, adotando estratégias variadas de acordo com o contexto em que se inscreve.

Como assinala o autor, os professores são parte importante de um projeto educativo e podem aparecer como sombras, representantes ou sujeitos. Aparecem em destaque quando algo foge ao contrato de neutralidade política e comportamental estabelecido entre os docentes e a sociedade representada pelo Estado, desencadeando um estado de Pânico Moral acionado pela desconfiança no poder que os professores detém sobre a parte fraca da sociedade, ou seja, sobre suas crianças. Por meio desse tipo de abordagem, torna-se possível desenvolver estudos que objetivem explicitar os imperativos práticos e ideológicos da gestão do Estado sobre a identidade dos professores, identificadas por meio da observação de determinadas regras de conduta profissional, das condições de ingresso, desempenho e valorização da carreira, bem como pela atribuição de certas qualidades, funções e papéis sociais que os documentos governamentais, tais como os materiais de orientação curricular e as propostas pedagógicas oficiais declaram esperar destes profissionais.

Outros estudos demonstram que o Estado não detém o controle exclusivo da gestão das identidades dos professores. Conforme demonstrou a pesquisadora norte-americana, Mary Dalton (1996), o cinema de Hollywood em particular, se coloca como outra instância capaz de gerir a identidade docente. A autora analisou 26 filmes veiculados nos Estados Unidos, nos quais a imagem do bom professor e da boa professora é construída com base no tipo heroico que, dotado de uma personalidade especial, luta contra a instituição escolar e os colegas acomodados para desempenhar seu papel dentro do mais alto nível de comprometimento estético-ético-político. Retratados como tipos renegados, indivíduos fora do convencional, o bom professor / boa professora dos filmes de Hollywood se envolve pessoalmente com seus alunos, quase sempre rompendo com as regras institucionais para ajudá-los a completarem a transição entre a escola e o mundo exterior. No entanto, conclui a autora, os professores aparecem como tipos heroificados e individualizados. Jamais atuam em grupo, 
não concebem a escola e o ensino como um trabalho coletivo. Por isso, esses filmes rendem belos "espetáculos", porém, os professores neles retratados jamais conseguirão promover mudanças duráveis na instituição escolar porque não acreditam na escola como instituição pública e tampouco conseguem articular um projeto coletivo de mudança da escola e do ensino. ${ }^{1}$

Mais preocupado em entender os currículos escolares em suas relações com as histórias de vida dos professores, Ivor Goodson (2010) destaca a importância das vozes do professor no processo de investigação sobre a escola, defendendo que a análise das questões curriculares e das práticas pedagógicas pode se beneficiar da atenção para com a história de vida dos educadores e com o que eles tem a falar, pois a sua forma de atuar dentro do contexto escolar está diretamente ligada às suas experiências. O autor argumenta que os dados sobre as vidas dos professores constituem fatores importantes para os estudos de investigação educacional. As razões que ele apresenta para tal residem no fato de que os estilos de vida dos professores, dentro e fora da escola, bem como as suas identidades e culturas ocultas têm impacto sobre os modelos de ensino assim como sobre as práticas educativas. De igual modo, ele considera que os estágios e decisões referentes à carreira só podem ser analisadas no seu próprio contexto (Goodson,2010:72), o que nos leva a concluir que os entrelaçamentos entre estilos pessoais e subjetivos com os contextos institucionais e as prescrições profissionais interferem nas concepções e práticas docentes e será a análise desses dados que permitirá ao pesquisador compreender elementos únicos do processo de ensino. Para o autor, os estudos referentes às vidas dos professores situam o indivíduo em relação com a história do seu tempo, permitindo-nos encarar a intersecção da história de vida com a história da sociedade, esclarecendo, assim, as escolhas, contingências e opções que constituem os contextos de ensino, em suas práticas e representações.

Na confluência das contribuições de Goodson, Isabel Lélis (2008:56) considera que a história social dos professores se apresenta como um terreno permeado por diversas histórias que se entelaçam, remetendo-nos para a

${ }^{1}$ Dentre os filmes analisados pela pesquisadora, se encontram: Ao Mestre com Carinho; Mr. Holland: adorável professor; Escola da desordem; dente outros. 
construção do campo intelectual da educação e da profissão; das relações entre os professores e o Estado; da construção da escola e dos saberes que nela circulam e da própria história dos professores como sujeitos ativos no processo de constução da profissão. Se o estilo pessoal e os recursos advindos de sua história particular ganham peso na definição das identidades desses profissionais, as suas inserções institucionais e posições sociais também interferen nas concepções de mundo, do conhecimento e do ofício - compondo outro traço forte na definição dos atributos desses profissionais. Afirma-se, por meio desse tipo de abordagem, o caráter subjetivo da própria profissão, que pode ser observado por meio do estudo das trajetórias docentes, recomposta tanto no âmbito individual, como nos contextos institucionais.

Se tomarmos as contribuições destes autores para refletirmos sobre a condição docente nos dias atuais, seremos levados de volta ao sentimento de mal estar-profissional, já referido anteriormente. O processo de expansão das oportunidades escolares tem levado ao aumento das responsabilidades sociais dos professores, ampliando, também, as exigências sobre os resultados do seu trabalho, obrigando os professores a modificarem o modo como vinham desenvolvendo o seu ofício. Isso requer um processo de renegociação identitária, colocando o professor diante de seus limites profissionais. Esse processo exacerba, também, o sentimento de desamparo dos professores frente às autoridades governamentais que, muitas vezes, não têm respostas para o encaminhamento de problemas cotidianos, tal como o da violência urbana (dentre outros) que tem interferido, cada vez mais, na dinâmica das escolas situadas em locais de risco.

Outro aspecto que aparece como pano de fundo dos estudos citados tem relação com o que Dubet (2006) chamou de declínio da instituição. Trata-se, em linhas muito gerais, de encarar o crescente descrédito nos benefícios da modernidade, com suas promessas de inclusão e ascensão social pela escola, bem como de enfrentar o questionamento ao credo no potencial redentor do conhecimento científico. Acrescente-se a essas questões, o fim das utopias políticas apoiadas na exemplaridade de sociedades organizadas segundo o modelo comunista e socialista. É claro que todos esses processos são dinâmicos e passíveis de reversão intelectual, política e profissional. Contudo, constituem ingredientes que, no mínimo, exercem um efeito negativo para 
a conformação de identidades engajadas, otimistas e confiantes no valor da ação de seu trabalho e, logo, de sua atuação profissional, agravando o sentimento de mal-estar profissional.

\section{O pêndulo profissionalização / proletarização}

A esse respeito, os estudos do pesquisador espanhol José Manoel Esteve (1999) têm sugerido uma atenção especial para as relações entre as novas demandas educacionais e a saúde dois professores. O autor associa essa sensação de mal estar a um conjunto de mudanças sociais que ocorreram nos últimos anos, tais como o advento da escola de massas; o desenvolvimento de fontes de informação alternativas à escola, a mudança nas expectativas em relação ao sistema de ensino e o aumento das exigências em relação ao trabalho do professor, provocando a ruptura do consenso em torno aos objetivos do ensino, ao papel da escola e às funções do professor. Tal situação foi agravada, por um lado, pela difusão das críticas sociológicas ao funcionamento da escola no sistema capitalista, como nos referimos anteriormente, assim como pela desvalorização salarial do professor que agravou a desvalorização social. Os reflexos mais visíveis do mal estar que atinge os professores podem ser observados na grande incidência de pedidos de licença para tratamento de saúde, em particular aquelas atribuídas a transtornos psíquicos que estão sendo tratados como síndrome do esgotamento profissional, também conhecida como burnout.

Tais efeitos foram agravados nos últimos anos pela adoção de políticas de caráter democratizante. Se, por um lado, essas políticas expressam importantes avanços dos movimentos sociais e da própria democracia, a sua implantação tem sido feita, muitas vezes, de modo demagógico, desconsiderando as necessidades de se criarem condições adequadas para sua efetivação e continuidade. Assim, ao mesmo tempo em que trazem ganhos para a população em geral, também representam maior instabilidade para a categoria docente - que se vê obrigada a ampliar o seu raio de atuação, participando da gestão administrativa e político-social e, ao mesmo tempo, submeter o seu trabalho à apreciação pública não especializada. Conforme observou a pesquisadora 
da Universidade Federal de Minas Gerias, Dalila Andrade Oliveira (2004), essa situação configura os processos de flexibilização e precarização do trabalho docente, confluindo para a sua desprofissionalização.

Os estudos selecionados consideram, ainda, as mudanças provocadas na organização do trabalho pedagógico e nas representações sobre a profissão docente, operadas nos últimos 50-60 anos com o advento da escola de massas. As consequências da progressiva universalização do ensino sobre o trabalho dos professores da educação básica originaram questões centrais nos estudos sobre a profissão docente, em especial nos estudos de caráter sociológico. Como observou Nóvoa (2002), nos últimos cinquenta anos, o processo de universalização do ensino levou a que a escola e os professores assumissem uma importância cada vez maior e, ao mesmo tempo, mais complexa. Por isso mesmo, os professores também se encontram cada vez mais expostos à avaliação pública e, acrescentamos nós, vêm sendo submetidos a diferentes esquemas de medição dos resultados de seu trabalho, submetidos a um sem número de avaliações, índices e rankings para medir o nível de aprendizagem dos alunos e definir a posição da escola, do sistema ou do país nas escalas hierárquicas produzidas pelos organismos de regulação da educação.

Por outro lado, os processos de estabilização e aprofundamento democrático têm reforçado as expectativas de inclusão social por meio da escolarização. Nesse processo, a adoção de políticas de diversidade, tendo em vista garantir os direitos de grupos específicos está atuando sobre as orientações políticas para a educação, introduzindo novas demandas ao trabalho do professor, como por exemplo, a ampliação de conhecimentos e disposições para atuar sobre alunos com necessidades especiais, tais como deficiências físicas e psíquicas; grupos beneficiados por cotas raciais, grupos que abrangem políticas de diversidades sexuais, dentre outras demandas. Este processo tem contribuído para uma exacerbação das tarefas docentes e, diante da falta de infraestrutura para apoiar os professores no atendimento a essas novas demandas, temos assistido a um processo de precarização do trabalho escolar (Oliveira:2004), com consequências negativas na saúde dos professores (Esteve:1999).

A questão sinalizada nos leva a outro tipo de abordagem que tem exercido forte influência nas análises históricas e sociológicas sobre a profissão docente. Esta provém das chamadas teorias da proletarização. Os artigos 
publicados no Brasil, ainda na década de 1990, em um dossiê temático da Revista Teoria e Educação (1994) apresentam as linhas gerais desse debate teórico, identificando seus principais autores e suas teses centrais, envolvendo pesquisadores de nacionalidades diversas.

Um autor central nesse debate é o pesquisador norte-americano, Michel Apple (2000). Ele aborda a perda de controle dos professores sobre a seleção, organização e produção dos saberes que constituem a matéria prima de seu trabalho, identificando aí, um dos principais fatores de sua desqualificação profissional. Por sua vez, o pesquisador espanhol, Mariano Enguita (1994) observa o aspecto de ambigüidade da docência que, segundo o autor, estaria a meio caminho entre a profissionalização e a proletarização. Compartilhando características de ambos os extremos, os docentes encontram-se submetidos à autoridade de seus empregadores ao mesmo tempo em que lutam para ampliar sua margem de autonomia no processo de trabalho e suas vantagens em relação à distribuição de renda, ao poder e ao prestígio. Tal situação é demonstrada a partir da análise das características dos grupos profissionais solidamente constituídos: competência, vocação, licença, independência e auto-regulação. A tese central de Enguita é a de que os docentes encontram-se submetidos a processos cuja característica e resultado são os mesmos para a maioria dos trabalhadores assalariados : a proletarização.

De modo geral, os teóricos da proletarização identificam como principal fator desse processo a lógica racionalizadora do capital que impõe a rotinização do trabalbo, o excesso de especialização, e a hierarquização, contribuindo para a desqualificação (separação entre concepção e execução do trabalho) e falta de autonomia (perda de controle e de poder decisório sobre o próprio trabalho) dos professores. De certo modo, Marta Jiménz Jáen (1994) problematiza as teorias da proletarização docente, ressaltando que esse processo assume formas específicas que nem sempre permitem a assimilação dos professores à classe operária. Assim, enquanto os teóricos da proletarização consideram as analogias com a classe operária nas quais as diferenças existentes entre as duas categorias tendem a desaparecer, a autora lembra que, de modo inverso, as diferenças encontradas são reveladoras das especificidades do processo sofrido por esta categoria profissional. O próprio Enguita (1994:44) afirma que (...) nada permite esperar que os docentes venham a se 
converter em um grupo profissional ou em um segmento a mais do proletariado, no sentido forte desses dois conceitos, pois eles se movem dentro de um leque de possibilidades cujos extremos continuam contidos dentro dos limites da ambiguidade própria das semi profissões.

A definição dependerá, sobretudo, da capacidade da categoria alcançar uma unidade e solidariedade positivas no sentido de resistir às pressões postas pelos manipuladores do poder. A esse respeito, vários autores têm assinalado a importância da gestão coletiva do trabalho docente. Assim, por exemplo, Antonio Nóvoa (2002) chama a atenção para o modo tradicional de organização do trabalho docente nas instituições de ensino, destacando, por um lado, o caráter solitário e pessoal do ofício docente e, por outro, alertando para a importância da dimensão coeltiva do trabalho escolar, denunciando, ainda, a inexistência, nesta, de espaços e tempos de partilha entre pares. Sem deixar de reconhecer as diferenças que marcam a identidade particular de cada instituição de ensino, outros autores como Hutmacher (1992) e Perrenoud (1993) fazem referência à existência de uma cultura dominante que, em geral, não permite a circulação de idéias e dificulta a auto-organização e cooperação entre os docentes. Em tal ambiente, os professores acabariam assumindo uma postura de resistência às possíveis mudanças.

Por esse ponto de vista, a abordagem sócio-histórica do processo de profissionalização docente tem colocado para os pesquisadores a necessidade de enfrentar a compreensão de uma situação extremamente ambígua, pois, ao mesmo tempo em que os professores alcançaram relativa estabilidade e regularidade em seu processo de trabalho, eles também se encontram submetidos ao controle do Estado, coerente com a condição de funcionários públicos. Desse modo, a legitimidade intelectual e a visibilidade social, então adquiridas, se chocam com os mecanismos de controle e de gestão das identidades profissionais dos professores, limitando a sua autonomia. Essa ambivalência que caracteriza a profissão docente - metade intelectuais (livre-pensadores) e metade representantes do Estado (burocratas) - representa, de certa forma, um dilema na definição da identidade profissional desse grupo. Nesse aspecto, a construção de uma abordagem sócio-histórica da temática em questão representa um avanço para a compreensão das particularidades que constituem o processo de profissionalização da categoria docente. 


\section{A história da profissionalização docente na longa duração}

Partindo de uma abordagem que chama de sócio-bistórica, o pesquisador português, Antonio Nóvoa (1987) propõe um conceito de profissão que aponta para uma nova chave de leitura dessa problemática, que se faz a partir de uma dupla dimensão e da percepção da existência de quatro etapas ou momentos do processo de profissionalização da atividade docente, que podem ser estudadas tanto numa perspectiva diacrônica quanto numa perspectiva sincrônica. Para Nóvoa, pode-se definir profissão como o (...) conjunto dos interesses que se relacionam com o exercício de uma atividade institucionalizada, da qual o indivíduo extrai seus meios de subsistência, atividade que exige a posse de um corpo de saberes e de saber-fazer e a adesão a condutas e a comportamentos, notadamente de ordem ética, definidos coletivamente e reconbecidos socialmente. (Nóvoa, 1987: 49)

As duas dimensões sempre presentes em uma profissão referidas por Nóvoa são, respectivamente, o saber e a ética. Para este autor, uma profissão se caracteriza, por um lado, por um conjunto de conhecimentos e técnicas adquiridos pela experiência e, sobretudo, através de uma formação prévia. A posse de um corpo de saberes e de saber-fazer próprio, específico e autônomo com relação aos outros domínios do conhecimento, é uma das dimensões essenciais do processo de profissionalização de uma atividade; bem como a formalização dos saberes condiciona mudanças na própria organização do trabalho. Este corpo de conhecimentos e técnicas deve ser passível de ser reproduzido e transmitido a outros e não pode ser analisado de forma desligada das suas condições de produção e difusão. A competência técnica e científica concedida pelo domínio deste corpo de conhecimentos é um dos principais argumentos utilizados pelos praticantes de uma determinada atividade para profissionalizar as suas funções e melhorar o seu status sócio-econômico. Este corpo de saberes, entretanto, não é jamais um produto acabado; está em uma constante reelaboração e é fruto de uma conjugação entre os projetos do grupo profissional e as demandas da sociedade onde se encontra inserido. Desta perspectiva, a análise sócio-histórica de um grupo profissional implica que se preste grande atenção às mudanças nas suas relações com o saber. 
A outra dimensão assinalada é a dimensão ética ou deontológica. O exercício de uma profissão remete-se a normas e a comportamentos éticos que orientam a prática profissional e as relações que se estabelecem entre os próprios praticantes e entre eles e os demais atores sociais. O código deontológico, seja ele formal ou informal, é portador de valores de ordem ideológica ou moral que visam defender e melhorar o status e o prestígio social dos membros do grupo profissional. Da mesma forma que o corpo de saberes, esta ética não é imutável, está em constante transformação, acompanhando, por um lado, a evolução dos saberes e, por outro, as mudanças nas relações entre o grupo profissional e os diferentes grupos sociais com os quais interage.

De outro ponto de vista, a profissionalização deve ser entendida como um longo processo que compreende quatro etapas fundamentais: o exercício em tempo integral, a licença estatal, a formação e a associação. Estas etapas não se sucedem linearmente ao longo do tempo. Correspondem aos grandes movimentos de um grupo profissional, mesmo reconhecendo que eles se caracterizam por progressos e recuos, de forma frequentemente contraditória. Para Nóvoa, estes momentos fortes marcam o processo de profissionalização de uma atividade e através da sua análise é possível reconstruir o seu percurso histórico.

A primeira etapa do processo de profissionalização consiste, portanto, na prática de uma determinada atividade em tempo integral, ou ao menos, enquanto ocupação principal. A questão da profissionalização só se coloca a partir do momento em que certo domínio social é ocupado por um conjunto de indivíduos que lhe consagram a maior parte do seu tempo de trabalho, buscando desta forma a sua subsistência. A segunda etapa supõe a criação, pelas autoridades públicas ou estatais, de um suporte legal para o exercício da atividade, sob a forma, por exemplo, de uma licença ou diploma. Este momento é particularmente importante para as profissões de tipo funcionário ou burocráticas, como é o caso da profissão docente, porque ela define um quadro legal de acesso à profissão. Normalmente, este quadro estabelece as condições necessárias, particularmente as que se relacionam com as competências exigidas para o ingresso na profissão, bem como institui procedimentos de recrutamento bem definidos. A definição do conteúdo destas 
competências será objeto de disputa entre o Estado e os diferentes grupos profissionais. Por outro lado, o status legal delimita o campo de exercício profissional e se constitui em um dos mais importantes instrumentos de que os profissionais dispõem tanto para a proteção e melhoria dos seus privilégios, quanto para a reivindicação do monopólio da atividade que exercem. A terceira etapa supõe o estabelecimento de procedimentos para a aquisição do corpo de saberes e de saber-fazer próprio da profissão, através de uma formação específica, especializada e longa. Do ponto de vista do autor, esta formação não pode ser adquirida apenas pelo aprendizado prático e deve conter referências teóricas e, em princípio, deve ser oferecida em um quadro acadêmico e institucionalizado. As instituições de formação não transmitem apenas conhecimentos e técnicas, mas contribuem também para a difusão de normas éticas e deontológicas e para o desenvolvimento de um espírito de solidariedade entre os futuros membros do corpo profissional. A quarta etapa se constitui na organização de associações profissionais com múltiplos objetivos: definir as normas de acesso á profissão; controlar o seu exercício; permitir a demarcação, preservação e alargamento do campo social de exercício da profissão; defender os interesses sócio-econômicos e profissionais dos seus membros; proteger as normas éticas e deontológicas estabelecidas. Estas associações podem ter status e papéis muito diferenciados, de acordo com as diferentes profissões e seu poder é também bastante heterogêneo. De qualquer forma, a sua constituição significa um momento importante no processo de organização de uma profissão.

Nóvoa chama atenção para o fato de que estas dimensões e etapas devem ser estudadas em estreita relação com a evolução do status social dos membros de uma profissão, já que não se pode esquecer que o processo de profissionalização é um empreendimento coletivo de mobilidade social. Assim, a história de um grupo profissional deve tomar como eixo central a inserção e as funções sociais do grupo em questão, bem como os projetos de sociedade de que são portadores. Desta perspectiva, igualmente, deve-se abandonar totalmente a idéia da existência de um tipo ideal de profissão que se configuraria como um parâmetro para se estudar o processo de institucionalização de um determinado grupo profissional. Cada grupo deve ser estudado em sua própria gênese e desenvolvimento. 


\section{Breve balanço da produção recente}

Para além das matrizes teóricas aqui destacadas, é importante identificar, ainda que de modo indicativo e pontual, os avanços atuais e as perspectivas futuras que se colocam em relação ao estudo da história da profissão docente no Brasil e em Portugal. Começaremos por apresentar um balanço retrospectivo que incide, sobretudo, na produção de estudos publicados até os anos 1990 e procura atualizar algumas afirmações pertinentes a esse período, para, posteriormente, vislumbrar perspectivas atuais e tendências futuras.

Com base em um levantamento preliminar, nós constatamos algumas características comuns no que tange à produção acadêmica sobre o tema mais geral: Profissão Docente. Em ambos os países, chama a atenção a grande quantidade de estudos que se voltam para o tema da profissão docente, sendo mais numerosa no que se refere às suas condições atuais no que tange à sua história. Nesse conjunto constatamos, uma maior incidência de estudos sobre a formação docente, em detrimento de temáticas que se voltam para a carreira profissional, condições de trabalho e associativismo docente. ${ }^{2}$

Embora não tenhamos uma investigação sistemática sobre o período mais recente, podemos afirmar que os estudos voltados para o associativismo docente, ganharam maior coerência e consistência em função dos Encontros ligados à formação de uma rede internacional de pesquisas sobre associativismo e sindicalismo docente, organizados no Rio de Janeiro, nos anos de 2009; 2010 e 2011. Tais encontros contribuíram para reunir a dispersa produção de pesquisas sobre esta temática num site próprio, além de viabilizarem a publicação de uma coletânea sobre o mesmo tema (Dal Rosso:2011). ${ }^{3}$

Em Portugal, balanço realizado por Áurea Adão, publicado em 1993, registra que, até o início dos anos 1990, a preocupação com a formação de professores suplantou o interesse pelo estudo do associativismo docente, embora

\footnotetext{
2 Em pesquisa anterior, foram levantados 26 artigos publicados nas três principais revistas brasileiras da área da Educação (segundo avaliação da CAPES), cobrindo os anos de 2000 a 2006. Nessa amostra, foi possível observar uma acentuada preocupação com o problema da formação docente (70\%), em detrimento dos estudos que analisavam questões relacionadas com a carreira e as experiências de associativismo docente (30\%).

3 Cf http://nupet.iesp.uerj.br/rede.htm acesso em 05 de junho de 2012, 22 h.
} 
este último tema se faça presente em estudos de natureza mais abrangente, mas que, no escopo de suas análises, acabavam atribuindo atenção especial às experiências de associativismo, tal como o demonstram os estudos de Fernandes (1987); Nóvoa (1987) e Adão (1984), dentre outros. ${ }^{4}$

Outro aspecto que, segundo a autora, se fazia comum no âmbito da produção sobre profissão docente até os anos 1990 remete-se ao predomínio de estudos que se voltam para os professores primários, relegando o estudo sobre os professores secundários (ou do ensino médio) a um segundo plano. A esse respeito, é possível atualizar o balanço da produção em História da Educação tomando como base o texto de Jorge Ramos do Ó (2007) no qual o autor analisa a produção de pesquisas ligadas à pós-graduação em educação em instituições portuguesas, desenvolvidas entre 1990 e 2004. Entre aquelas que versam sobre os atores escolares, o autor identifica algumas temáticas-chave, a saber: Associativismo Docente (Amado:2000); Formação de Professores (Mogarro: 2001) e Cultura Docente (Araújo:1993; Felgueiras: 2002 e Resende : 2001). Alguns desses estudos têm circulado no Brasil, desde os anos 1990, em função dos intercâmbios estabelecidos entre pesquisadores portugueses e brasileiros interessados no estudo da História da Educação, conforme detalharemos adiante. A formação de redes de pesquisadores interessados em temáticas comuns, bem como nas histórias conectadas tem levado á publicação de um conjunto variado de estudos, em ambos os países.

Exemplar do intercâmbio entre pesquisadores é o livro intitulado História da Escola em Portugal e no Brasil: circulação e apropriação de modelos culturais, organizado por Joaquim Pintassilgo, Marcos Cezar de Freitas, Maria João Mogarro e Marta Maria Chagas de Carvalho, publicado em 2006. No referido livro, a existência de uma seção relativa à cultura impressa e circulação

4 Áurea Adão (1993) reconhece que, em Portugal, a história da formação docente tem merecido maior atenção que o estudo de outros aspectos a ela referentes. Segundo a autora, até a década de 1990, poucos foram os estudos sobre o associativismo docente, localizando, no início da década de 1970, o primeiro estudo sobre o tema (Gomes Bento. História do movimento associativo dos professores do ensino secundário - 1891 a 1932), que veio a ser refundida e ampliada após o 25 de abril de 1974, incluindo o associativismo dos professores primários. Já na década de 1980, despontam os estudos de Áurea Adão (1984) e Antonio Nóvoa (1987) dedicaram capítulos especiais ao tema, enquanto Rogério Fernandes ocupou-se das primeiras tentativas de organização dos professores, nos inícios do século XIX. 
de saberes pedagógicos apresenta resultados de pesquisas relativas aos modelos pedagógicos e culturais em circulação no Brasil e em Portugal, observando as suas formas de apropriação pelos atores sociais implicados na vida escolar. Nessa linha, são analisados manuais pedagógicos de formação de professores e outros impressos e equipamentos como livros, bibliotecas e revistas especializadas, utilizados por professores atuantes nos dois lados do Atlântico. Seguem-se a este, mais dois livros, o primeiro, organizado por Joaquim Pintassilgo e Lurdes Serrazina (2009), analisa o aspecto institucional na formação de professores em perspectiva histórica e contém estudos em parceria com pesquisadores brasileiros (Cf: Mogarro e Martinez; Mogarro e Zaia). A esta publicação, seguiu-se a publicação do livro intitulado Formação de Professores em Portugal, organizado por Joaquim Pintassilgo, Maria João Mogarro e Raquel Henriques (2010), centrando foco no percurso histórico da formação de professores em Portugal, nos séculos XIX e XX.

No Brasil, a utilização dos impressos como fonte para o estudo da história da educação em geral e para o estudo da profissão docente em particular se apresenta como uma linha de pesquisa bastante profícua, inclusive na perspectiva comparada. Sobre esta linha de pesquisa, cabe citar o estudo pioneiro de Denice Catani (2003) que, a partir da análise da Revista de Ensino, reconstitui a história da Associação Beneficente do Professorado Público de São Paulo, articulando temas como o associativismo docente e a utilização dos impressos na organização do ensino nesse estado. Merece registro, ainda, a publicação de Vicentini e Lugli (2009), sob o título História da profissão docente no Brasil: representações em disputa, resultado do esforço por sistematizar a história dos movimentos docentes no Brasil dos séculos XIX e XX, em especial por meio da identificação de suas associações profissionais. Nesse empenho, logram mapear um campo de estudos ainda pouco explorado pela produção de pesquisas no âmbito da história da educação. Dentre os estudos que tomam como base as fontes impressas, há os que optam por trabalhar com os manuais pedagógicos e a circulação de saberes (Correia e Batista, 2002); com os livros e revistas para professores e a circulação de modelos pedagógicos (Bastos e Mogarro: 2009; Xavier e Mogarro: 2011) ou, ainda com a análise comparada de revistas de educação e ensino no Brasil e em Portugal (Fernandes: 2008; Carvalho et all: 2007), além de outras abordagens em curso. 
Ainda na linha da produção resultante de intercâmbios Brasil-Portugal, merece registro o desenvolvimento de pesquisas interinstitucionais que desenvolvem estudos articulados sobre a história da profissão docente. Desse modo, possibilitam o conhecimento simultâneo dos processos de construção social da profissão docente a partir de recortes temporais e espaciais específicos. Nessa linha, já se encontram em circulação estudos sobre os impactos das Reformas Pombalinas no processo de profissionalização docente (Cardoso:2002; Mendonça e Cardoso: 2008; Mendonça: 2010 e 2011); sobre emergência das escolas normais (Lopes e Martinez: 2007; Mogarro e Martinez:2009); sobre o associativismo docente em contextos de construção democrática (Lelis e Xavier: 2009; Xavier:2011); sobre valores católicos e representações de professores (Magaldi e Neves:2007), dentre outros.

Os estudos comparados sobre a história da profissão docente desenvolvido por brasileiros e portugueses apresentam aos interessados diferentes perspectivas e instrumentos de análise que poderão compor um instigante repertório teórico-metodológico de incursão no tema. Conforme observaram Souza e Martinez (2009:210), tais estudos apresentam, hoje, um olhar problematizador, tendo como denominador comum a análise das práticas discursivas que operam no interior dos diferentes espaços sociais, muitas das quais priorizam as práticas que estiveram ligadas ao processo de institucionalização das chamadas ciências da educação nos dois países.

\section{Considerações Finais:}

Com relação à temática da história da profissão docente, cumpre destacar, fazendo nossas as palavras de Catani (2000), que só muito recentemente o termo bistória da profissão docente vem sendo formalmente utilizado nos trabalhos que se debruçam, de uma perspectiva histórica, sobre as questões referentes à formação de professores, aos saberes e atividades docentes, e mesmo à organização da categoria do magistério. Para ela, o que a expressão possui de elucidativo é, justamente, a noção unificadora das várias dimensões do exercício profissional do magistério, cuja concepção exige a análise simultânea e integrada dessas mesmas dimensões (opus cit, p. 587). 
Remetendo-se à análise da produção sobre o tema apresentada nos encontros acadêmicos da área, Catani aplica a esta produção a avaliação de Nunes (1998) acerca do conjunto de trabalhos apresentados por pesquisadores brasileiros ao I Congresso Luso-Brasileiro de História da Educação, para a primeira ainda perfeitamente válida. Segundo Nunes (opus cit), apesar da inegável renovação da área nos anos mais recentes, esta se caracteriza por uma dispersão temática e mesmo metodológica, que fragiliza os resultados obtidos. Na visão desta última autora, a área de história da educação ainda não apresenta (referindo-se à situação brasileira) um acúmulo de produção que aponte para a existência de campos de pesquisa especializados, claramente delimitados.

Em que pesem as lacunas ainda existentes no âmbito dos estudos sobre a história da profissão docente, as tradições de pesquisa em circulação aqui identificadas representam avanços importantes no que tange à produção de uma percepção diferenciada acerca de determinadas representações e expectativas em torno do papel do professor e das potencialidades e limites da escola. Este é, a nosso ver, o ponto a partir do qual esses estudos provocam o redimensionamento das análises vigentes sobre a função da escola e o papel do professor. Nesses trabalhos, tornou-se possível perceber alguns princípios centrais que contribuem para melhor compreendermos a problemática da profissão docente. Dentre estes, destacamos: 1) a importância por reconhecer que a escola e o professor são construções históricas e, portanto, nem sempre foram vistos ou se fizeram perceber da forma como são vistos hoje em dia; 2) a percepção de que a escola é responsável pela permanente criação de um público, ou seja, pela socialização dos indivíduos, que, cada vez mais, dependem da experiência escolar e, portanto, da intervenção do professor para se tornarem pessoas capazes de conviver em sociedade; 3) a constatação de que, nos dias atuais, a escola e o professor estão assumindo uma importância cada vez maior e, ao mesmo tempo, tendem a se tornar alvo de duras críticas, sendo, frequentemente, responsabilizados pelos insucessos escolares. Por fim, devemos ressaltar a importância de se considerar as potencialidades, os limites e as particularidades da atuação do professor e do trabalho escolar de modo a evitar tratá-los como panacéia para a solução de todas as mazelas sociais. Só assim será possível atenuar a culpa que 
o chamado senso comum atribui ao professor e à escola quando as crianças não aprendem, alimentando a falsa idéia de que a escola e o professor podem superar os obstáculos interpostos aos excluídos em uma sociedade desigual e injusta.

\section{Referências Bibliográficas}

ADORNO, Teodor (1995). Tabus acerca do magistério. In Educação e emancipação. Trad. de Wolfgang Leo Maar. Rio de Janeiro: Paz e Terra, 1995.

APPLE, Michael (W. (2006). Ideologia e Currículo. Porto Alegre, Artmed.

BRANDÃO, Margarida (1999). Modos de ser Professor. Lisboa, Educa.

CATANI, Denice Bárbara (2000). Estudos de História da Profissão Docente. In LOPES, E. M. T.; FARIA FILHO, L. M.; VEIGA, C. G. 500 Anos de Educação no Brasil. Belo Horizonte: Autêntica.

(2003). Educadores à meia luz: um estudo sobre a Revista de Ensino da Associação Beneficente do Professorado Público de São Paulo (1902-1918). Bragança Paulista, EDUSF. CARDOSO, Tereza Fachada Levy (2002). As luzes da educação: fundamentos, raizes históricas e prática das aulas régias no Rio de Janeiro (1759-1834).Bragança Paulista, EDUSF.

CARVALHO, L. M; FERNANDES, A. L. C; XAVIER, L. N.(2007). Aspectos da imprensa periódica educacional em Lisboa e no Rio de janeiro (1921-1963). In: Revista Brasileira de História da Educação, v. 15, pp. 79-99.

CORREIA, Antonio Carlos da Luz e SILVA, Vivian Batista da (2002). Manuais Pedagógicos Portugal / Brasil, 1930 a 1971 - produção e circulação internacional de conhecimentos pedagógicos. Lisboa, Educa.

DALTON, Mary, (1996). O currículo de Hollywood: quem é o "bom" professor, quem é a "boa" professora? In: Educação \& Realidade, vol. 21, n. 1, Porto Alegre (pp.97-122).

DUBAR, Claude. (1997). A socialização. Construção das identidades sociais e profissionais. Porto: Porto Editora.

(2005). A socialização: construção das identidades sociais e profissionais. São Paulo: Martins Fontes.

(1998). Trajetórias sociais e formas identitárias: alguns esclarecimentos conceituais e metodológicos. In: Educação e Sociedade. Campinas: Unicamp/Cedes, v. 19, n. 62, abr., p. 13-30.

DUBET, François (2002). Le Declin de l'Institution. Paris: Éditions du Seuil, 2002.

El declive de la institución - profesiones, sujetos e individuos ante la reforma del Estado. Traducción de Luciano Padilla. Barcelona: Gedisa, 2006.

ENGUITA, M. F. (1989). A face oculta da escola: Educação e trabalho no capitalismo. Porto Alegre, Artes Médicas.

(1991) A ambigüidade da docência: entre o profissionalismo e a proletarização. In: Revista Teoria \& Educação, n. 4. Porto Alegre, RS: Pannonica Editora Ltda, p. 41-61. 


\section{história e Sociologia da Profissão docente}

ESTEVE, Manoel (1999) O mal estar docente. Santa Catarina. EDUSC.

FERNANDES, Ana Lúcia Cunha (2008). O impresso e a circulação de saberes pedagógicos: apontamentos sobre a imprensa pedagógica na história da educação. In: MAGALDI, Ana e XAVIER, Libania (2008). In: Impressos e História da Educação: usos e destinos. Rio de Janeiro, Sete Letras. GOODSON, Ivor F (1995). Currículo, teoria e história. Petrópolis, Vozes.

(2010). A representação dos docentes: trazer de volta os professores. In: Conhecimento e vida profissional: estudos sobre educação e mudança. Porto, Porto Editora.

HUTMACHER, Walo, (1992). A escola em todos os seus estados: das políticas de sistemas às estratégias de estabelecimento, In: Antônio Nóvoa (coord.), As organizações escolares em análise. Public. Dom Quixote, Instituto de Inovação Educacional. Lisboa.

JAEN, Marta Jiménez (1991). Os docentes e a racionalização do trabalho em educação: elementos para uma crítica da proletarização do trabalho docente. In: Teoria e Educação, n. 4. Porto Alegre, RS: Pannonica Editora Ltda, p. 74-18.

LAWN, Martin (2000). Os professores e a fabricação de identidades. In A. Nóvoa \& J. Schriewer (Eds.). A difusão mundial da escola (pp.69-84). Lisboa: Educa.

LÉLIS, Isabel (2008) A construção social da profissão docente no Brasil: uma rede de histórias. In: TARDIFF, M. e LESSARD, C. O Ofício de Professor. Petrópolis, Vozes, p.54-66.

e XAVIER, L. N (2009). O Ofício docente na voz de suas lideranças sindicais. In Sísifo: Revista de Ciências da Educação. Universidade de Lisboa. http://sisifo.fpce.ul.pt/

LOPES, S. e MARTINEZ, S. (2007) A emergência de escolas normais no Rio de Janeiro do século XIX: Escola Normal do Município da Corte e Escola Normal de Campos. In Revista Brasileira de História da Educação-SBHE. N 15.

MAGALDI, A. e NEVES, C. V. (2007). Valores católicos e profissão docente: um estudo sobre representações em torno do magistério e do "ser professora" (1930-1950). In Revista Brasileira de História da Educação-SBHE. N ${ }^{\circ} 15$.

MENDONÇA, Ana Waleska (2011). A construção da identidade do professor do ensino secundário, normal e profissional: uma abordagem comparativa. Projeto de pesquisa. Mimeo.

(2011). A Reforma Pombalina dos estudos menores (1759-1794) e o processo de profissionalização dos professores secundários no mundo luso-brasileiro In: História da Profissão Docente no Brasil (Coleção Horizontes da pesquisa em história da educação no Brasil).1 ed.Vitória/ES : EDUFES, v.7, p. 37-58.

.(2010) A fragmentação dos estudos secundários e seus efeitos sobre o processo de profissionalização dos professores. Sísifo/Revista de Ciências da Educação, n.11, p.5 - 14.

E CARDOSO, T. F. (2007). A gênese de uma profissão fragmentada. In Revista Brasileira de História da Educação-SBHE.

MOGARRO, M. J. e MARTINEZ, S. (2009). Os primeiros estudantes do ensino normal: origens sociais e formação de professores na segunda metade do século XIX em Portugal. In $A$ Escola Normal de Lisboa e a formação de Professores. Lisboa, Edições Colibri, pp. 61-78.

MOGARRO, M. J. e ZAIA, I. B. (2009).Do Palácio ao Calvário: escolas de formação de professores em Portugal na segunda metade do século XIX. In A Escola Normal de Lisboa e a formação de Professores. Lisboa, Edições Colibri, pp. 41-60.

NOVOA, A. (2002). Formação de Professores e Trabalho Pedagógico. Lisboa, Educa. 
(1998). La Profession enseignante en Europe: Analyse historique et sociologique. Lisboa: Educa,1998, pp. 147-185.

(1994). Para o estudo sócio-histórico da gênese e desenvolvimento da profissão docente. Teoria \& Educação. n.4, p.109-139.

(1987). Le Temps des Professeurs. Analyse socio-bistorique de la profession enseignante au Portugal (XVIII- XX siècle), Lisboa: Instituto Nacional de Investigação Científica, 2 v.2. Ó, Jorge Ramos do (2007) - Métodos e processos na escrita científica da História da Educação em Portugal: um olhar sobre 44 teses de doutoramento aparecidas entre 1990-2004. In PINTASSILGO, Joaquim e outros (org.) - A História da Educação em Portugal. Balanço e perspectivas. Porto: Edições Asa.

PINTASSIlgO, J.; AlVES, L. A.; CORREIA, L. M. e FElgUEIRAS, M. (orgs.) (2007) A História da Educação em Portugal: balanço e perspectivas. Porto, Editora ASA, pp.35-72.

FREITAS, M.; MOGARRO, M.; e CARVAlHO, M.. (2006). História da Escola no Brasil e em Portugal: circulação e apropriação de modelos culturais. Lisboa, Edições Colibri.

e SERRAZINA , L. (2009). A Escola Normal de Lisboa e a formação de Professores. Lisboa, Edições Colibri.

; MOGARRO, M. e HENRIQUES, R.P.;(2010). A formação de Professores em Portugal. Lisboa, Edições Colibri.

PERRENOUD, P.(1993) Práticas pedagógicas profissão docente e formação: perspectivas sociológicas. Tradução de Helena Faria, Helena Tapada, Maria Carvalho, Maria Nóvoa. Lisboa: D. Quixote. OLIVEIRA, Dalila Andrade (2004). A reestruturação do trabalho docente: precarização e flexibilização. In: Eduação e. Sociedade, Campinas, vol. 25, n. 89, set./dez. p. 1127-1144. http://www. scielo.br/pdf/es/v25n89/22614.pdf

SANCHES, Maria de Fátima Chorão (2004). A construção discursiva da liderança escolar dos professores: da práxis revolucionária ao tempo de normalização. Revista Portuguesa de Educação. Universidade do Minho, número 17 (2), pp. 132-178.

SOUZA, Donaldo Bello e MARTINEZ, Silvia Alícia (orgs.) (2009). Educação Comparada, rotas de além mar. São Paulo, Xamã (pp. 167-220).

XAVIER, Libania Nacif (2011). Identidade docente nos jogos de poder: um ensaio a partir dos movimentos docentes brasileiro e português. In ROSSO, Sady dal. Associativismo e Sindcalismo em Educação, Brasília, Paralelo 15.

e MOGARRO, Maria João (2011). Itinerários Profissionais de Professores

no Brasil e em Portugal: Redes de Intercâmbio no Contexto de Expansão do Movimento da Escola Nova. In Revista da ASPHE, 15 (36), Pelotas, (pp.117-136). 